\title{
LA EDUCACIÓN PATRIMONIAL EN LA DIDÁCTICA DE LAS CIENCIAS SOCIALES EN PRIMARIA
}

\author{
María Pilar Molina Torres \\ Universidad de Córdoba
}

\begin{abstract}
RESUMEN: El siguiente trabajo tiene como objetivo presentar un proyecto que muestra las posibilidades de la puesta en práctica de un itinerario didáctico para el conocimiento del patrimonio histórico. El proyecto trabajado en el tercer ciclo de Educación Primaria tuvo como finalidad el desarrollo de una serie de actividades centradas en una etapa histórica del patrimonio cordobés: la Edad Antigua, y volcadas en un blog para su uso didáctico en el aula. La metodología elegida fue esencialmente constructivista, donde los alumnos tendrán que ir obteniendo sus propias conclusiones a través de diversas tareas que irán desde investigaciones de campo a presentaciones en PowerPoint realizadas por ellos mismos. Del mismo modo, lo más destacado de esta experiencia fue que la transmisión de conocimientos del profesor pasó a un segundo plano para centrarse en actividades construidas autónomamente para incitarlos a reflexionar e interaccionar entre compañeros.
\end{abstract}

PALABRAS CLAVE: Educación patrimonial, metodología, primaria, trabajo cooperativo, TIC.

\section{THE PATRIMONIAL EDUCATION IN THE DIDACTICS OF THE SOCIAL SCIENCES IN PRIMARY}

\begin{abstract}
The following paper aims to present a project that shows the possibilities of the implementation of a didactic itinerary for the knowledge of historical heritage. The project worked on the third cycle of primary education was aimed at developing a series of activities focused on a historical stage of Cordoba heritage: the Old Age, and dunks in a blog for educational use in the classroom. The methodology chosen was essentially constructive, where students will have to go their own conclusions obtained through various tasks that go from field research to PowerPoint presentations made by themselves. Similarly, the highlight of this experience was that the
\end{abstract}


transmission of knowledge from teacher went to the background to focus on activities autonomously built to encourage them to reflect and interaction among peers.

KEYWORDS: Heritage education, methodology, primary, team work, TIC.

Recibido: 09/09/2016

Aceptado: 09/01/2017

Correspondencia: M. ${ }^{a}$ Pilar Molina Torres, Universidad de Córdoba, Avda. San Alberto Magno s/n, 14071 Córdoba. Email: pilar.molina@uco.es.

\section{INTRODUCCIÓN}

En este artículo abordaremos un proyecto educativo elaborado para trabajarlo en el tercer ciclo de Educación Primaria, puesto que los contenidos relacionados con el patrimonio cultural ya han sido tratados previamente. Sin embargo, y a pesar del interés que suscita el conocimiento patrimonial, su presencia en el currículo es imperceptible desde el punto de vista documental y material. Por otra parte, y centrándonos en el alumnado, contaríamos con veinticuatro alumnos en total, los cuales provienen de hogares de clase media, con lo que tienen acceso a recursos informáticos en su entorno, ya sea internet, smartphones, tablets, etc, de modo que en mayor o menor medida están familiarizados con estos recursos, con independencia de que sepan usarlos adecuadamente o no. Así pues, nuestra experiencia fomentará el uso del blog y tendrá como finalidad no sólo su utilización dentro del aula, sino el estudio del patrimonio de la Antigüedad que aún se conserva en Córdoba. Para ello se pone en marcha una experiencia didáctica que busca trabajar concretamente la época romana y los contenidos que se relacionan con las actividades sociales y económicas, además de las creencias y las repercusiones que las reformas administrativas romanas tuvieron en el entorno cultural de Corduba. En definitiva, y una vez finalizada la secuencia didáctica, los alumnos tendrán adquiridas las destrezas necesarias para poder hacer uso de la plataforma con la que han trabajado.

En consecuencia, el uso del blog es una herramienta útil para fomentar la autonomía, la creatividad y el interés de nuestros alumnos y alumnas, sin tener que ceñirnos a una metodología tradicional y transmisiva (Molina, 2016a). Dicho de esta manera, no hay duda de que los contenidos volcados en esta herramienta virtual permiten que sea consultada, modificada, revisada y editada por un individuo. De tal forma que un blog se retroalimenta de la información suministrada, en este caso concreto por nuestros alumnos de Primaria. Y es aquí donde la participación y la implicación del trabajo colaborativo se desempeña en primera persona, y por extensión se transmite a los docentes, la familia y al propio centro educativo. Asimismo, es conveniente resaltar que este formato utilizado adecuadamente es una alternativa viable y de fácil acceso para trabajar los contenidos de Ciencias Sociales, ya que al mismo tiempo la planificación de las tareas hace que se gestione de forma autónoma los links, el reparto de funciones, la coordinación del trabajo en grupo, etc. 
Este trabajo se enmarca en el proyecto de investigación (HAR2015-68059-C21-R) (P)atrimonio (A)rqueológico, Nuevas (T)ecnologías, (T)urismo, (E)ducación y (R) estauración Social: un (N)exo Necesario para la ciudad histórica.

\section{El proyecto educativo}

En un estudio de Aznar y Soto (2010), se pone de manifiesto la importancia que la alfabetización o competencia digital tiene en la escuela, hasta el punto de ser Andalucía la comunidad autónoma que en Educación Infantil, Primaria y Secundaria logra una mayor creación, participación e implicación del uso de Edublogs en las aulas. Los autores realizan este trabajo tomando como muestra 374 blogs educativos contenidos en los directorios de blogs Científicos y Educativos de España, Blogfesores y Aulablog. Teniendo como premisa esta investigación, nuestro proyecto docente nos permitió incorporar a la práctica de aula el uso del blog. Esta alternativa digital fue innovadora en el ambiente educativo desde el momento que los alumnos se vieron inmersos en un proceso de aprendizaje que se diferencia de los formatos tradicionales de enseñanza.

Asimismo, la apuesta por este recurso TIC supuso que el docente pase de agente directo en todo el proceso a mediador y los alumnos de agentes pasivos a promover el interés propio, colectivo e incluso del profesor. Por tanto, el aprendizaje no se construyó de manera individual sino cooperativa, además de adquirir los conocimientos y el manejo de esta herramienta digital desde lo más sencillo hasta lo más complejo. De esta manera, el blog de aula fue el lugar idóneo para servir de biblioteca, de punto de encuentro entre docente y alumnos, de elemento motivador, de agente social y colaborativo entre iguales, y en definitiva de factor estratégico para aunar competencias, emociones, habilidades y destrezas que se comparten y se comunican en primera persona. El uso del Edublog es una microesfera de todos estos factores que componen una estrategia didáctica puesta en práctica en el aula y fuera de ésta.

A través de esta estrategia didáctica vamos a intentar conseguir la combinación de ambos campos: el blog y la importancia que el patrimonio histórico romano ha dejado en Córdoba. Para ello acercaremos dicho patrimonio a las aulas, aunque somos conscientes de que a menudo es desconocido para los alumnos, a pesar de que algunos de los monumentos de la ciudad afloran en su superficie sin darle el valor que se merecen. Es por todo esto que comenzaremos la experiencia buscando información acerca de la Corduba romana y su importancia como centro administrativo para el resto del Imperio romano. Dicha búsqueda se realizará a través de enlaces web que encontrarán en el blog, leerán diferentes textos bien sobre cultura clásica, bien acerca de las creencias, las actividades económicas, los eventos sociales de un/a romano/a de Hispania. Así deberán responder a una serie de cuestiones que les lleven a concretar, reflexionar y exponer la información, previa puesta en común con sus compañeros de grupo. Antes de la realización de cada tarea, se han trabajado las ideas previas que tienen, escuchándolas sin decir si éstas son correctas o no. Se compartirán entre todos una vez finalizada la búsqueda de información y hechas las actividades.

Sin embargo, tampoco se pretende que se sustituya por completo la didáctica tradicional, que esta nueva "alfabetización" digital suprima los recursos tradicionales, pero sí buscamos que el alumnado considere igual de importante y útil tanto un tipo de recursos como otros, que lo vean como algo familiar, con finalidades específicas 
según lo que estemos buscando. Asimismo, uno de los propósitos de esta investigación es trabajar las siguientes competencias educativas recogidas en la legislación actual (LOMCE), y que se corresponden con el método de trabajo mejor relacionado con la temática:

- Comunicación lingüística. Puesto que utilizaremos el lenguaje como medio para conseguir que se comuniquen en el aula tanto de forma oral como escrita, expresando sus emociones y pensamientos, para que aprendan a escuchar, dialogar y resolver conflictos por medio del diálogo.

- Conciencia y expresiones culturales. Entre otras cosas trabajaremos la concienciación por el cuidado de su entorno cultural, la influencia del ser humano sobre él despertando un espíritu crítico, observando la realidad y analizando noticias y publicaciones sobre el patrimonio de su ciudad.

- Competencia digital. A través de la búsqueda y selección de la información, y en consecuencia transformándola en conocimiento. Hacer un uso correcto del blog extrayendo de él su máximo potencial y empleándolo para la resolución de problemas reales, desde un enfoque comunicativo y social, trabajando en equipo para lograr resultados creativos.

- Competencias sociales y cívicas. Con la utilización de nuestro blog los alumnos van a poder comprender la evolución histórica de su entorno y de su cultura, asimismo propiciaremos el desarrollo de habilidades sociales que favorezcan el diálogo para resolver problemas de convivencia y así darse cuenta de que forman parte de la sociedad en la que viven.

- Aprender a aprender. Fomentaremos la motivación en el alumno para que compruebe que puede aprender por él mismo despertando su interés a través de actividades creativas. A través de nuestro blog, los alumnos tendrán que extraer la información importante a partir de algunos textos seleccionados.

- Sentido de la iniciativa y espíritu emprendedor. El trabajar en grupo conlleva la reproducción de ideas de cada uno de sus miembros y su contribución. Del mismo modo, se genera la confianza necesaria para sentirse sujeto activo en la toma de decisiones y aportaciones individuales o grupales.

Parece una tarea ardua el diseñar de forma que podamos conseguir a través del blog de aula los objetivos propuestos y una serie de contenidos, pero la realidad es bien distinta. Si sabemos trasladar la realidad al aula, aquellos aspectos que les interesan a nuestros alumnos, teniendo en cuenta su edad, añadiéndole toques creativos como pueden ser vídeos, imágenes, fotos, etc, de forma que sea interactivo, el resultado será cuanto menos enriquecedor. Su carácter innovador, atrae la atención de los alumnos favoreciendo su participación y su interés por aprender. Además, debido a su facilidad de creación y a la amplia gama de posibilidades que presenta para su diseño, hace que cada blog sea único, lo que atribuye un carácter esencialmente creativo a la elaboración del docente.

\section{Objetivos del trabajo}

Para Echazarreta (2009): "El éxito de un proyecto colaborativo depende en buena medida de una adecuada planificación y estructuración previa, que articule 
tanto los objetivos que se pretenden alcanzar como los contenidos del proyecto y la metodología que se va a aplicar en su desarrollo". Por tanto, son varios los factores que influyen y permiten que un proyecto sea exitoso. Ahora bien, y como nos dice Ovejero (1990): "en el aprendizaje cooperativo debe tenerse en cuenta el principio general de intervención, que consiste en que un individuo solamente adquiere sus objetivos si el resto de los participantes adquieren el suyo". Es razonable que en un contexto donde el trabajo colaborativo, también denominado cooperativo, influye en los objetivos programados, la metodología y los recursos utilizados en el aula configuran un tipo de aprendizaje bien por recepción o por descubrimiento (Caballero, 2000).

Todos estos aspectos ayudan a alcanzar los objetivos planteados en esta propuesta didáctica, de ahí que se plantee un objetivo general que intente describir las metas que se pretenden lograr:

- Valorar la importancia de la cultura arqueológica en nuestra ciudad (Córdoba) y promover una actitud de compromiso con la conservación de su patrimonio histórico.

Gracias a este objetivo de carácter general podemos entender la trascendencia de la propuesta. Pero además debemos concretar unos objetivos didácticos más específicos que recojan los contenidos que se van a trabajar:

- Conocer cómo trabaja un/a arqueólogo/a.

- Entender cómo y qué fue la conquista de Hispania.

- Reconocer los pueblos prerromanos que existieron en la Península Ibérica antes de la llegada de los romanos.

- Comprender las características principales de la sociedad hispanorromana, así como su economía.

- Reflexionar acerca de la importancia de las creencias hispanorromanas.

- Explicar cómo era una ciudad romana y las actividades de ocio que se llevaban a cabo.

\section{Metodología y desarrollo del trabajo}

El método de enseñanza por el que se optó se basa fundamentalmente en una metodología activa y participativa puesto que las actividades buscan implicar al alumno de forma directa en su propio aprendizaje. Además también se emplea una metodología investigativa-constructivista, desde la cual y como punto de partida, el docente tiene en cuenta las ideas previas que el alumnado posee sobre el tema a trabajar para, a partir de ahí, acompañarlo en su proceso de construcción del conocimiento. También se utilizan distintos tipos de agrupamientos dando prioridad al trabajo en grupo y a estrategias de aprendizaje cooperativo. A lo que es necesario añadir que en el proceso de aprendizaje, y concretamente con la utilización de nuevas tecnologías, el constructivismo se centra en la construcción de ese conocimiento y no en su reproducción. Del mismo modo, como plantea Hernández (2008): "un componente importante del constructivismo es que la educación se enfoca en tareas auténticas; tareas que son las que tienen una relevancia y utilidad en 
el mundo real". Por este motivo, ha sido necesario concienciar a nuestros alumnos de que la metodología de la presente propuesta no tendría un carácter repetitivo, estático y desmotivador, sino que pudimos otorgarles la libertad necesaria para expresarse, crear y aprender del error como una oportunidad para avanzar a un mejor conocimiento.

Por lo que respecta a la temporalización de la propuesta didáctica serán necesarias ocho sesiones. Una primera sesión para la detección de ideas previas y organización de grupos, seis sesiones para el desarrollo de actividades y una última sesión de evaluación.

Actividades iniciales (una sesión): la actividad inicial titulada "Cómo vivía un romano" consiste en una introducción a la cultura romana, así como al conocimiento de los monumentos más destacados de Hispania romana (Figura 1). Su finalidad es abordar este tema de una manera didáctica y motivadora, haciéndoles partícipes de manera activa durante el desarrollo de la actividad, a su vez esta tarea nos servirá para realizar una pequeña evaluación inicial y comprobar sus conocimientos previos. Para su realización contaremos con el ordenador para volcar la información en el blog de aula y con un proyector para visualizar un PowerPoint con imágenes de la ciudad de Roma.

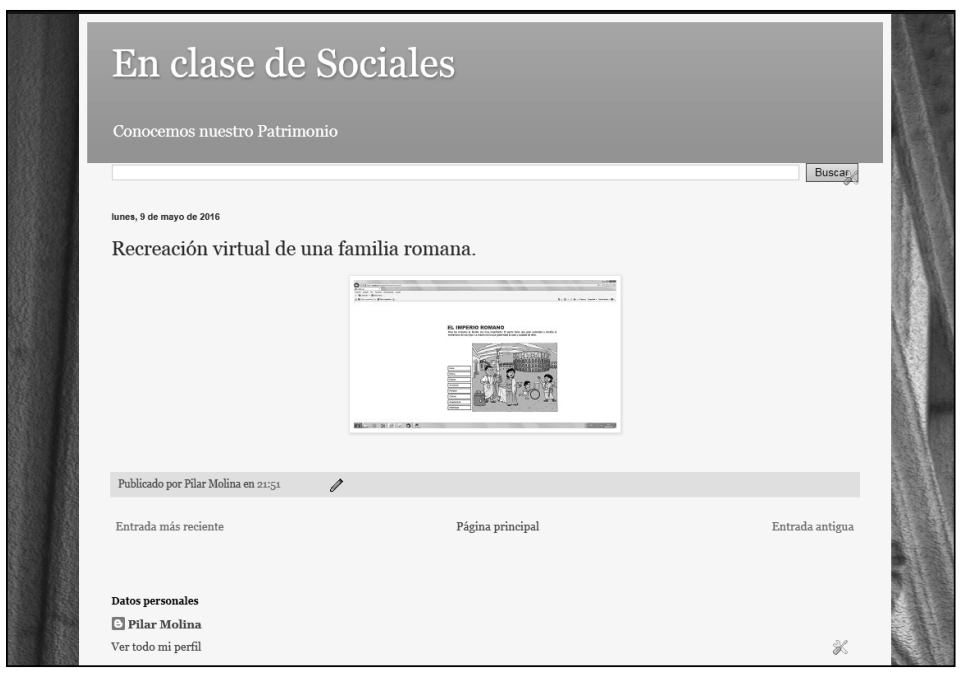

Figura 1. Recreación virtual de una familia romana. Fuente: http://enclasedegeografiaehistoria.blogspot.com/

La actividad se realizará en dos partes. Por un lado, la lectura de un cuento que reflejará un día en la vida de un niño y una niña romanos que se acompañan de imágenes. La docente realizará la lectura del cuento en voz alta a toda la clase, mientras que el alumnado deberá de poner en práctica su atención y escucha para averiguar qué vamos a aprender, para captar su atención la historia integra un misterio que consiste en conocer las costumbres diarias de unos niños romanos 
en Hispania. Dicha lectura será interrumpida en diferentes partes por una serie de imágenes en PowerPoint, que recogerán: lugares y monumentos más característicos de Roma, vestimenta y jerarquía social. Las representaciones expuestas serán comentadas por todos, a su vez el visionado contará con una serie de espacios destacados en diferentes zonas arqueológicas de la península ibérica, en las que podrán observar el legado romano con el que contamos hoy día en nuestro país. Terminada la puesta en común y el visionado dividiremos la clase en dos grandes grupos heterogéneos que serán organizados por la docente. Se les dará una lámina en A3 a cada grupo, compuesta de fotos del Imperio romano y de algunas ciudades patrimoniales en la actualidad, en el reverso de las láminas contarán con una serie de preguntas que deberán contestar y que estarán relacionadas con los contenidos que acabamos de ver.

Actividades de desarrollo (seis sesiones): en la primera sesión de la fase de desarrollo comenzaremos proyectando un vídeo en el aula que colgaremos en el blog y tendrá como finalidad transmitir los contenidos sobre la conquista de Hispania y las divisiones administrativas en la que se divide (Figura 2). Esta actividad titulada: ¡Por ahí vienen los romanos!, se complementa con la entrega del siguiente cuestionario que deben responder por grupos:

- ¿Quiénes conquistaron Hispania?

- ¿Durante qué guerras consiguieron el control de la navegación por el Mediterráneo?

- ¿A quiénes vencieron en dichas guerras?

- ¿En cuántas partes se divide Hispania?, ¿cuáles son sus nombres?

- ¿Cuál fue el último pueblo en someterse a la conquista?

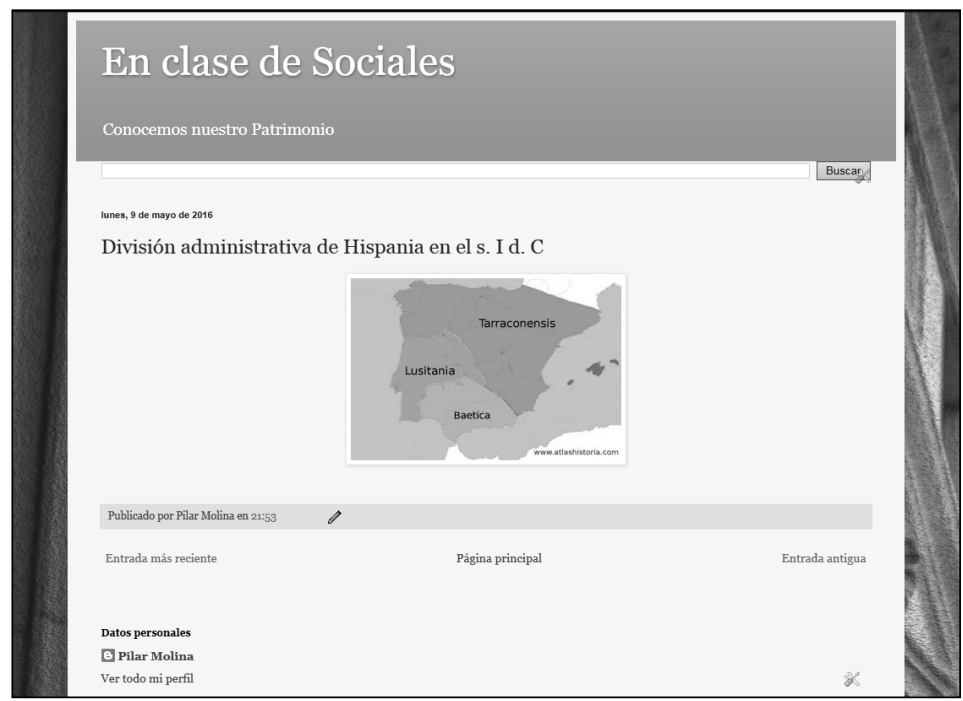

Figura 2. División administrativa de Hispania en el s. I d. C. Fuente: http://enclasedegeografiaehistoria.blogspot.com/ 
A continuación, la docente les hace una pequeña introducción de lo que van a ver en el vídeo y durante la proyección, los alumnos de manera individual, tienen que estar atentos para responder a las preguntas indicadas. Por último, se procederá a una puesta en común en gran grupo-clase, donde se responderán a las dudas que surjan y se corregirá el cuestionario.

Para completar el trabajo de aula y aprovechar el entorno que nos rodea, realizaremos un itinerario didáctico por la Corduba romana y la visita a diversos restos que se encuentran integrados en el urbanismo actual de la ciudad (Figura 3). Para ello, dividiremos la clase en cuatro equipos de investigación y cada uno de ellos será el encargado de recoger toda la información sobre un tema determinado, de tal manera que se especialicen en la temática elegida para posteriormente contársela al resto de grupos como auténticos expertos en la materia.

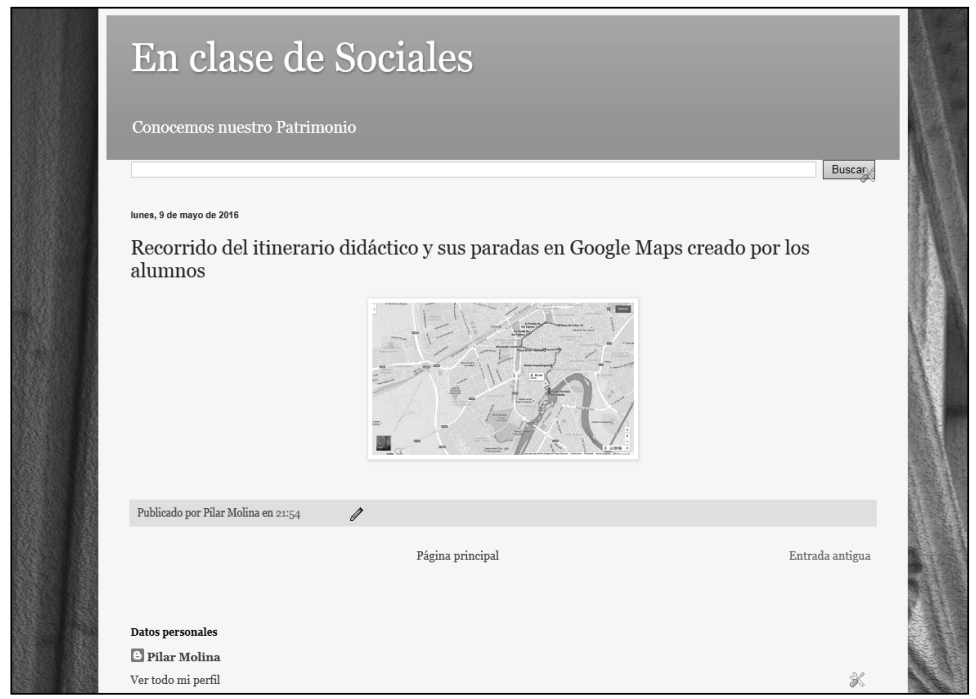

Figura 3. Recorrido del itinerario didáctico y sus paradas en Google Maps. Fuente: http://enclasedegeografiaehistoria.blogspot.com/

Las temáticas son las siguientes:

- Urbanismo de la ciudad romana: trazado urbano además de los edificios más importantes y su función.

- Actividades económicas del pueblo romano.

- La sociedad romana I: clases sociales y vida cotidiana según su grupo de pertenencia (las casas romanas, objetos y artesanía, etc.).

- La sociedad romana II: creencias religiosas y actividades de ocio.

- Paradas 1 y 2 (dedicamos la segunda sesión de desarrollo): Puerta del Rincón y Puerta Osario. En dichas paradas se trabajará el perímetro amurallado de la ciudad y las distintas puertas de acceso a ésta. Asimismo, se delimitará su conexión con el foro y la situación actual del Cardo y Decumano Máximos. 
- Paradas 3 y 4 (tercera sesión): Avenida Ronda de los Tejares, continuamos bordeando la muralla que rodeaba la ciudad. Los restos se encuentran in situ en el sótano de una entidad financiera cordobesa (Cajasur).

- Parada 5 (cuarta sesión): Puerta Gallegos. Aquí haremos una parada en un mausoleo funerario que muestra las formas de enterramiento de los grupos sociales privilegiados de Colonia Patricia, y su emplazamiento cerca del perímetro amurallado.

- Parada 6 (quinta sesión): Plaza de Las Tendillas. Aunque hoy día es la plaza central de la ciudad, en época romana continúa dando nombre a su situación estratégica con el nombre de foro. Los edificios principales dedicados a la administración, centro de culto imperial y lugar de encuentro de los ciudadanos tenían su localización en este espacio público.

- Parada 7 (quinta sesión): Templo de la calle Claudio Marcelo. La visualización del templo de Claudio Marcelo hará que los alumnos puedan recrear las creencias religiosas de la ciudad y el culto al emperador.

- Parada 8 (sexta sesión): Plaza Jerónimo Páez. Con la visita al museo arqueológico conoceremos las actividades de ocio de los romanos de Corduba, ya que se conservan en este edificio las gradas del teatro de la colonia y podremos viajar en el tiempo para descubrir cómo disfrutaba de los espectáculos teatrales un ciudadano romano. Aprovechando la entrada al museo, haremos una visita a la sala dedicada a la epigrafía, escultura, utensilios de menaje para la vida doméstica y por supuesto a las devociones que se han conservado en figuras de dioses romanos y orientales.

- Parada 9 (sexta sesión): Puente Romano. Finalmente, con esta última parada no solamente podemos apreciar la arquitectura romana sino el entorno del río Guadalquivir a su paso por la ciudad y la influencia que ha tenido a lo largo de todos estos siglos.

Es en esta última parada donde finaliza el itinerario. Aprovecharemos este espacio al aire libre para que los distintos equipos se reúnan y realicen una primera puesta en común de la información que han ido recogiendo. El objetivo es que se aseguren de que tienen los datos más significativos y resolver las dudas que les hayan podido surgir, para que con ayuda de la docente y el guía del itinerario se pueda resolver. Todas estas zonas serán explicadas por el guía que nos acompañará y la docente que en todo momento se mantendrá activa y participativa resolviendo las dudas de los alumnos. Al final de la visita nos reuniremos en asamblea donde se corregirá el cuadernillo de actividades y se volverá a incidir en aquellas cuestiones en las que el alumnado quiera profundizar.

Actividades finales (una sesión final): de vuelta al aula, dividimos la clase de nuevo en cuatro grupos que elaborarán un taller virtual con vídeos que recojan la experiencia vivida en la salida a Corduba. Para ello, cada grupo seleccionará en internet un enlace afín a la temática que les ha tocado trabajar durante el itinerario didáctico. De este modo, podrán exponer por grupos a sus compañeros cuáles han sido sus impresiones acerca del recorrido y proyectarles los vídeos, webquest o wikis que han seleccionado para la exposición. Con esta actividad se convierten en historiadores por un día, y en investigadores para comprender este nuevo contexto tanto histórico como virtual. 
Actividades complementarias: del mismo modo, contemplamos la necesidad de elaborar actividades relacionadas con el fomento de la lectura (Plan Fomento de Lectura y Biblioteca) que secuenciamos durante toda la experiencia didáctica. Nuestra actividad se ha titulado "Haciendo la Biblioteca del Colegio", y consiste en la lectura de un libro acerca de la temática que vamos a trabajar. Para evaluar esta actividad, cada alumno realizará una ficha bibliográfica del libro "Rómulo y Remo" de AnneCatherine Vivet-Rémy, que incluirá un resumen, los aspectos que más le han gustado, además de opiniones personales respecto a la temática de la obra en cuestión (Molina, 2016b). Todo ello será colgado en el blog de aula, para que tengan la referencia bibliográfica y puedan opinar en un espacio habilitado como foro para comentar la ficha que han confeccionado (Figura 4).

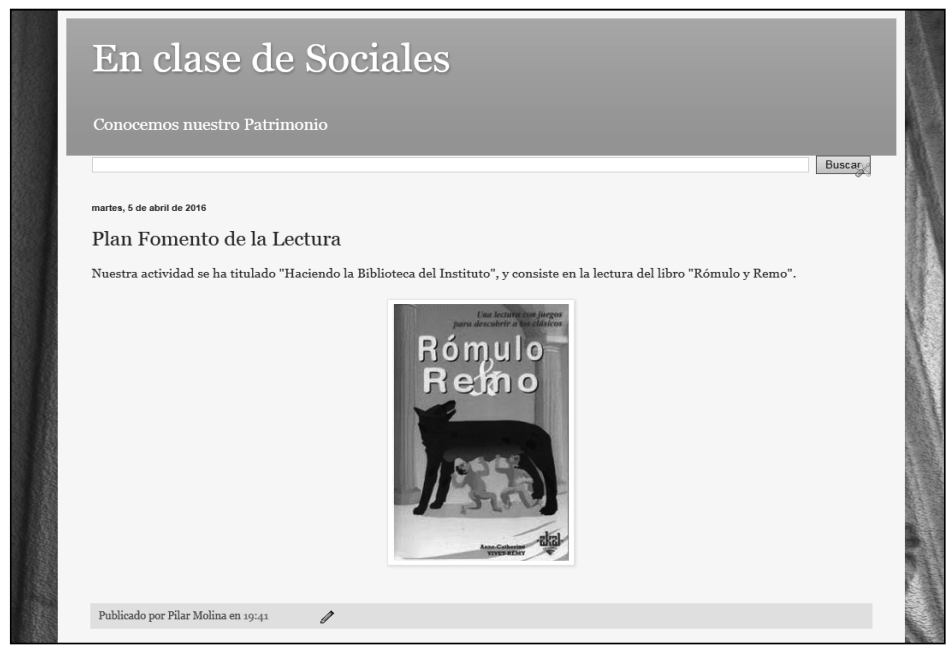

Figura 4. Actividad Plan Fomento de la Lectura.

Fuente: http://enclasedegeografiaehistoria.blogspot.com/

\section{Evaluación del proyecto}

Para evaluar hemos tenido como premisa que para que el alumnado aprenda es imprescindible su participación en las tareas propuestas y una actitud receptiva ante los nuevos conocimientos que les proporcionamos. Es obvio que la gestión colaborativa en el aula se fundamenta en el trabajo en común y con carácter esencialmente grupal.

Por otra parte, a lo largo de todo el proyecto la evaluación ha sido continua, flexible y ha permitido en todo momento la retroalimentación. De hecho, en asamblea hemos podido hacer un repaso general en todas las fases del proceso para dar respuesta a los interrogantes, organizar los recursos, adquirir nuevos aprendizajes y en consecuencia acometer las tareas que se estaban realizando y las que quedaban pendientes.

De modo que la autoevaluación del alumno ha sido clave para saber cómo evaluar. Las exposiciones finales, los trabajos de aula, el cuaderno de campo empleado en la visita guiada, y por supuesto los recursos TIC han supuesto un aprendizaje no 
sólo colectivo sino enriquecedor para que los alumnos puedan preguntarse: ¿qué he aprendido?, y ¿qué he aprendido a hacer? Asimismo y estableciendo diferentes niveles competenciales tanto el alumnado como la propia docente reflexiona sobre los factores que han intervenido en el proceso de enseñanza aprendizaje. Para ello, y con la finalidad de sondear las opiniones de los alumnos y poder averiguar si han aprendido de los errores, si el trabajo grupal ha funcionado, si la motivación para las actividades propuestas fue la adecuada, establecemos dos cuestionarios: uno dirigido al docente y otro a los alumnos (Tablas 1 y 2).

Tabla 1. Escala de valoración del profesor hacia los alumnos

\begin{tabular}{|l|l|l|l|l|}
\hline Aspectos a valorar. $\quad$ Alumno/a: & A & B & C & D \\
\hline Conoce y respeta el legado arqueológico de la Corduba romana. & & & & \\
\hline $\begin{array}{l}\text { Da respuesta correctamente a las cuestiones acerca del tema que } \\
\text { están trabajando. }\end{array}$ & & & \\
\hline Es capaz de manejar herramientas para investigar. & & & & \\
\hline Avanza en el proceso de aprendizaje investigativo. & & & \\
\hline $\begin{array}{l}\text { Reflexiona durante todo el proceso desde las ideas previas a las } \\
\text { ideas finales. }\end{array}$ & & & & \\
\hline Tiene curiosidad e interés por utilizar el blog de aula. & & & & \\
\hline $\begin{array}{l}\text { Trabaja de manera colaborativa y mantiene una actitud correcta } \\
\text { durante las sesiones. }\end{array}$ & & & & \\
\hline Muestra una actitud positiva y motivadora por aprender. & & & & \\
\hline Reconoce las principales características patrimoniales de Corduba. & & & & \\
\hline $\begin{array}{l}\text { Aporta ideas creativas al grupo y participa en las tareas grupales } \\
\text { e individuales. }\end{array}$ & & & & \\
\hline
\end{tabular}

Fuente: Elaboración propia.

Tabla 2. Autoevaluación del alumno/a

\begin{tabular}{|l|l|l|l|l|}
\hline Aspectos a valorar. & A & B & C & D \\
\hline $\begin{array}{l}\text { ¿Reconozco algunos elementos del legado romano que aún con- } \\
\text { servamos? }\end{array}$ & & & \\
\hline ¿He aprendido cosas sobre el patrimonio? & & & & \\
\hline ¿Sé qué es un foro y dónde se encontraba en esta ciudad? & & & & \\
\hline ¿Cómo ha sido mi comportamiento en el trabajo en grupo? & & & & \\
\hline ¿He colaborado para que mis compañeros aprendan? & & & & \\
\hline ¿Qué he aprendido sobre Corduba?, ¿y sobre los romanos? & & & & \\
\hline ¿Qué otras actividades te hubiese gustado trabajar? & & & \\
\hline $\begin{array}{l}\text { Valora con excelente, bueno, aceptable y regular el trabajo reali- } \\
\text { zado por el grupo. }\end{array}$ & & & \\
\hline $\begin{array}{l}\text { Si tú eligieras las actividades: ¿escogerías las mismas que se han } \\
\text { hecho en este proyecto? }\end{array}$ & & & & \\
\hline $\begin{array}{l}\text { ¿Te ha parecido interesante y útil el uso del blog en el aula para } \\
\text { desarrollar nuestro itinerario didáctico? }\end{array}$ & & & & \\
\hline
\end{tabular}

Fuente: Elaboración propia. 


\section{Resultados}

Para la implementación del itinerario didáctico por la Corduba romana se utilizaron varios recursos que afianzaron la interpretación del patrimonio histórico de la ciudad. En consecuencia, y siempre desde una metodología investigadora, conseguimos los objetivos planteados al inicio de la propuesta. Asimismo, el trabajo cooperativo en el aula y fuera de ella permitió un modelo inclusivo para el proceso de enseñanza aprendizaje (Lata y Castro, 2016).

En cuanto al uso del blog de aula, el alumnado estuvo dispuesto y motivado para hacer una búsqueda de los recursos digitales y con ello investigar acerca del itinerario que íbamos a realizar. Del mismo modo, la información que iban encontrando la colgaron en el blog para que los compañeros pudieran consultarla y mostrar que eran unos expertos en la materia. Los recursos didácticos que seleccionaron les ayudaron para identificar y diseñar el itinerario en Google Maps, y geolocalizar las diferentes paradas de la salida. De esta manera, todos participaron en la investigación y selección de la información más adecuada para organizar la ruta didáctica y asimismo decidir la localización para visitar los monumentos de las temáticas trabajadas. Finalmente, volcaron el recorrido completo de la salida que pudimos realizar.

Por lo que respecta a los cuestionarios, para conocer y evaluar las experiencias de cada alumno se tomó una muestra de carácter cuantitativo. Los datos recogidos fueron determinantes para interpretar las opiniones de los veinticuatro participantes. Para ello, contamos con una escala de valoración que refleja la adquisición de conocimientos actitudinales, conceptuales y procedimentales. En dicha escala, la valoración es $A, B, C$, o D, para $A$ el valor sería excelente, mientras que para D sería regular. De las cinco respuestas cerradas para cada uno de los cuatro valores posibles (Figura 5), los resultados analizados evidenciaron que tras la experiencia los alumnos podían reconocer elementos del patrimonio romano, que habían aprendido las características de dicha cultura y que sabían que es un foro y dónde se ubicaba. Sin embargo, en el

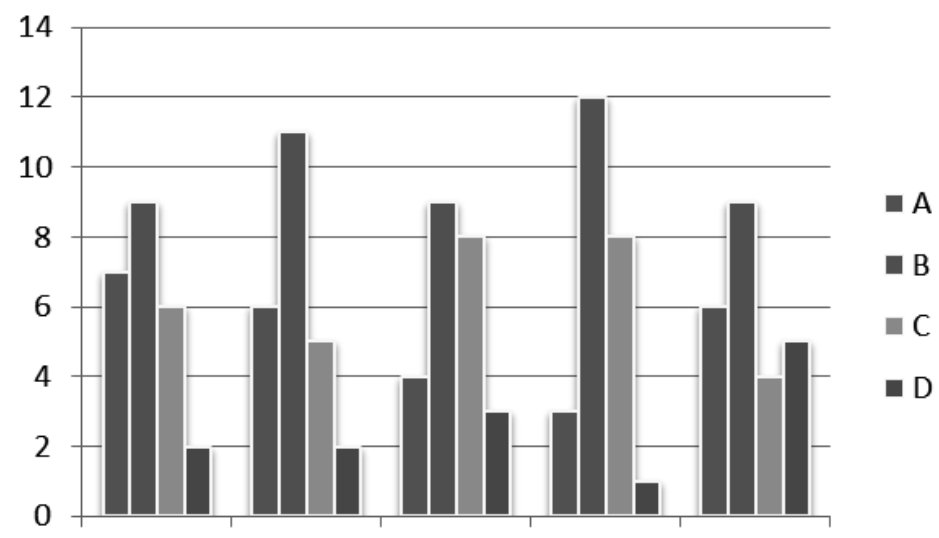

Cuestión 1Cuestión 2Cuestión 3Cuestión 4Cuestión 5

Figura 5. Gráfico para valorar las respuestas del alumnado 
momento de reflexionar acerca de su comportamiento en grupo y si el trabajo había sido colaborativo, los alumnos respondieron que sí habían trabajado en equipo de manera adecuada, aunque en cuanto a la ayuda grupal las respuestas fueron diversas demostrando que la cooperación entre ellos no había sido proporcionada.

Por otra parte, para estudiar las cuestiones de respuesta abierta y sus posibles significados desde un enfoque esencialmente subjetivo, la muestra tomada de la investigación cualitativa referida a los conocimientos aprendidos durante la propuesta didáctica, la elección de nuevas actividades diferentes a las puestas en práctica, la valoración del trabajo en grupo, y la utilidad del blog para diseñar y exponer el itinerario, reflejaron una respuesta positiva por conocer más acerca de la Córdoba romana, y no solo de esta etapa histórica sino de otras como la musulmana.

\section{Conclusiones}

Las conclusiones que podemos establecer a través de la práctica de esta experiencia didáctica y cultural que hemos desarrollado con una perspectiva interdisciplinar, se centran en la mejora de diversas competencias con el fin de concienciar al alumnado del patrimonio de su ciudad y del uso de las NNTT como complemento de este itinerario histórico-artístico. De hecho, las actividades se han centrado en el conocimiento del entorno más cercano al alumno, con la facilidad añadida de conocer las posibilidades que ofrece para identificar los principales elementos culturales y analizar desde una actitud crítica las características históricas que tiene nuestro patrimonio.

El itinerario se ha diseñado adaptándolo al tercer ciclo de Educación Primaria, y teniendo en cuenta en todo momento los intereses y las inquietudes que tuvieron por saber más acerca de este ámbito histórico. Para ello se trabajó en el aula con diversos recursos TIC que tuvieron como principal objetivo el desarrollo de la iniciativa personal y el trabajo colaborativo en grupos pequeños. La salida didáctica la realizaron en Google Maps, sabiendo previamente las paradas que íbamos a realizar. Del mismo modo, los vídeos, mapas, la ruta para documentar sus explicaciones fueron volcados en el blog de aula, también el libro para fomentar la lectura y las cuestiones trabajadas en la visita.

En definitiva, durante todo este proceso de enseñanza hemos conseguido descubrir un contexto determinado de nuestra Historia y de nuestro entorno más cercano. Desde esta perspectiva del patrimonio cultural, podremos "valorar" gracias a "conocer". Además, el ámbito al que va dirigida esta propuesta es al patrimonio arqueológico e histórico de la Corduba romana, donde el paso de la historia le ha proporcionado connotaciones, que al conocerlas, ayudan a entender la realidad actual y que permiten al alumnado sentirse parte del mismo.

\section{ReferenCias bibliográficAS}

Aguaded, J. I. y López, E. (2009). La blogosfera educativa: nuevos espacios universitarios de innovación y formación del profesorado en el contexto europeo. Revista electrónica Interuniversitaria de Formación del Profesorado, 12(3), 165-172. 
Arnaiz, P. y Azorín, C. M. (2012). El edublog como herramienta de aprendizaje para todos en el entorno virtual. Revista Didáctica, Innovación y Multimedia, 24, 1-14. Recuperado de https://ddd.uab.cat/pub/dim/dim_a2012m12n24/dim_a2012m12n24a3.pdf.

Ávila, R. M. (2003). La función del itinerario en la enseñanza y el aprendizaje del Patrimonio Histórico-Artístico. Íber: Didáctica de las ciencias sociales, geografía e historia, 36, 36-47.

Aznar, V. y Soto, J. (2010). Análisis de las aportaciones de los blogs educativos al logro de la competencia digital. Revista de Investigación en Educación, 7, 83-90.

Ballart, J. (1997). El patrimonio histórico y arqueológico: valor y uso. Barcelona: Ariel.

Caballero, J. D. (2000). Didáctica de las Ciencias Sociales, Geografía e Historia, para profesores de Educación Secundaria. Sevilla: MAD.

Calaf, R. (2010). Un modelo de investigación didáctica del patrimonio. Enseñanza de las ciencias sociales: revista de investigación, 9, 17-28.

Colom, A. J., Sarragona, J. y Vázquez, G. (1998). Educación ambiental y la conservación del patrimonio. Barcelona: Ariel.

Cuenca, J. M. (2014). El papel del patrimonio en los centros educativos: hacia la socialización patrimonial. Tejuelo, 19, 76-96.

Durán, J. F. (2011). La contribución del Edublog como estrategia didáctica. Electronic Journal of Research in Educational Psychology, 9(1), 331-356.

Echazarreta, C. (2009). La competencia "El trabajo colaborativo": una oportunidad para incorporar las TIC en la didáctica universitaria. Descripción de la experiencia con la plataforma ACME (UdG). UOC Papers: Revista sobre la sociedad del conocimiento, 8, 1-11.

Estepa, J., Domínguez, C. y Cuenca, J. M. (2001). Museo y patrimonio en la Didáctica de las Ciencias Sociales. Huelva: Universidad de Huelva.

Fontal, O. (2003). La educación patrimonial. Teoría y práctica en el aula, el museo e Internet. Gijón: Trea.

Fontal, O. (2006). Claves del patrimonio cultural del presente y desde el presente para abordar su enseñanza. Revista de Educación, 29, 9-31.

Fontal, O. (2011). El patrimonio en el marco curricular español. Revista de Patrimonio Cultural de España, 5, 21-44.

García, Z. (2009). ¿Cómo acercar los bienes patrimoniales a los ciudadanos? Educación Patrimonial, un campo emergente en la gestión del patrimonio. PASOS: Revista de turismo y patrimonio cultural, 7(2), 271-280.

García-Valcárcel, A., Hernández, A. y Recamán, A. (2012). La metodología del aprendizaje colaborativo a través de las TIC: una aproximación a las opiniones de profesores y alumnos. Revista complutense de educación, 23(1), 161-188.

González, R., García, F. y Gonzalo, N. (2011). Los edublogs como herramienta facilitadora en comunidades virtuales de aprendizaje. Relada, 5, 248-256.

Hernández, S. (2008). El modelo constructivista con las nuevas tecnologías: aplicado en el proceso de aprendizaje. Comunicación y construcción del conocimiento en el nuevo espacio tecnológico. Revista de Universidad y Sociedad del Conocimiento (RUSC), 5(2), 26-35. Recuperado de http://www.uoc.edu/rusc/5/2/dt/esp/ hernandez.pdf. 
Lata, S. y Castro, M. (2016). El Aprendizaje Cooperativo, un camino hacia la inclusión educativa. Revista Complutense de Educación, 27(3), 1085-1101.

Husillos, M. (2012). La Arqueología Virtual: Construyendo un puente entre la sociedad moderna y la escuela innovadora. Virtual Archaeology Review, 3, 36-39.

Martín, I. (2004). La webquest en el área de ciencias sociales: aprendizaje de las TIC en contextos educativos. Íber: Didáctica de las ciencias sociales, geografía e historia, 41, 77-96.

Molina, M. P. (2016a). El blog para descubrir el patrimonio natural en las aulas de primaria. Aula de innovación educativa, 248, 29-32.

Molina, M. P. (2016b). Una propuesta metodológica para el aprendizaje de las ciencias sociales en secundaria. Íber: Didáctica de las ciencias sociales, geografía e historia, 83, 55-60.

Ovejero, A. (1990). El aprendizaje cooperativo: Una alternativa a la enseñanza tradicional. Barcelona: P.P.U.

Rodríguez, M. E. y Bonilla, J. (2010). Inclusión y aplicación de las tecnologías en los centros educativos. Jaén: Formación Continuada Logoss.

Santolaria, A. (2014). La ciudad como recurso didáctico. Edetania, 45, 235-244.

Sobrino, D. (2012). Google Maps: localizar para aprender. Aula de Innovación Educativa, 217, 77-78.

Temprano, A. (2009). Webquest: Aproximación práctica al uso de Internet en el aula. Sevilla: MAD. 